\title{
Diagnostic and reliability model of an internal combustion engine
}

The article presents a diagnostic and reliability model of an internal combustion engine that allows to assess the reliability status of the engine's systems for a two-state model of operation and maintenance: functional - failed. The proposed diagnostic model is a qualitative-quantitative probabilistic model combining the reliability states of the engine systems with the values of the vibroacoustic diagnostic signal parameters. The conducted diagnostic and reliability experiments and simulation tests showed that based on the developed diagnostic and reliability model, it is possible to determine the reliability states of the engine.

Key words: diagnostics, internal combustion engine, diagnostic and reliability model

\section{Introduction}

The basic task of technical diagnostics is to assess the technical condition or correctness of the tasks performed by a technical object without its disassembly. The technical condition of the object is most often defined by a set of parameters defining the features of its elements, e.g. their geometric features, their mutual position, unbalance, quality of cooperation, etc. In complex mechanical objects, it is not always possible to fully assess the status of individual elements [4].

In operational practice, especially in the operation system of technical facilities, including internal combustion engines, the exact value of the state (wear) of individual elements of the object is often not required, as it is sufficient to receive qualitative classification of the state of the object or its systems. The qualitative assessment comes down to determining the reliability state of the object, systems and assemblies in the form of a binary evaluation: functional or failed.

A study of mutual relations between diagnostic parameters and the damage process described by means of reliability indicators was carried out based on correlation and regression studies for a locomotive engine [11]. The conducted correlation research allowed to choose parameters of the vibration signal, which best represent the process of engine damage $[7,10]$.

The aim of the work is to present the concept of a diagnostic and reliability model that allows to assess the technical (reliability) state of the internal combustion engine systems, adopting a two-state model of operation and maintenance: functional - failed. To determine the parameters of the diagnostic and reliability model, diagnostic and reliability tests of internal combustion engines were carried out based on a passive-reliability diagnostic experiment $[2,3,8]$.

\section{The general diagnostic model of the object}

The general model of the object can be presented, for example, in the form of a diagram, the so-called black box shown in Fig. $1[5,6]$.

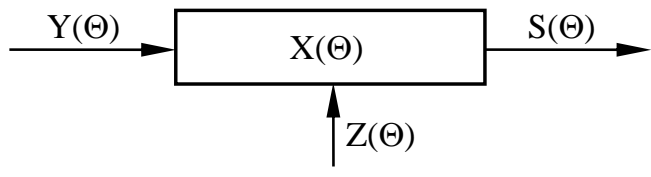

Fig. 1. Diagram of the object general model
This model can be described by the equation in the form:

$$
\mathrm{S}(\Theta)=\Phi[(\mathrm{Y}(\Theta), \mathrm{X}(\Theta)]+\mathrm{Z}(\Theta)
$$

where: $\mathrm{Y}(\Theta)$ - a set of operational parameters, also called input parameters, which can include, for example, the load status of the object, the amount of energy consumed, etc., $\mathrm{Z}(\Theta)$ - a set of environmental parameters, which include, among others, various kinds of interference in the surroundings of the object, the condition of the environment (temperature, humidity of air), etc., $\mathrm{X}(\Theta)$ - a set of features characterising the state of modules (sub-assemblies) of the object, their state of regulation, etc., $S(\Theta)$ - a set of output parameters generated during the operation of the object: related to its function (torque, rotational speed, etc.) and accompanying parameters (vibrations, noise, thermal processes, etc.), $\Theta$ - measure of aging of the object.

\section{Set of operational (input) parameters $Y(\Theta)$}

A set of operational (input, control) parameters of the object $\mathrm{Y}(\Theta)$ is a collection of elements:

$$
\mathrm{Y}(\Theta)=\left\{\mathrm{y}_{1}(\Theta), \mathrm{y}_{2}(\Theta), \ldots ., \mathrm{y}_{\mathrm{n}}(\Theta)\right\}
$$

where: $y_{i}(\Theta), i=1,2, . ., n-$ parameters characterising the object's operating status (state of regulation). These parameters can be: load, power supply status, rotational speed, operating conditions, state of regulation, etc.

It was assumed that during subsequent measurements (realisations), i.e. for subsequent time periods $\Theta_{n}$, elements of $y_{1}(\Theta), y_{2}(\Theta), \ldots, y_{n}(\Theta)$ of the set $Y(\Theta)$ are constant. The constant value of operational parameters for subsequent diagnostic measurements is a condition of repeatability of results for the same values of state parameters. Constant values of parameters from the set $\mathrm{Y}(\Theta)$ were obtained by providing a determined energy state described by: constant speed and constant control settings. Assuming that:

$$
\mathrm{y}_{1}\left(\Theta_{\mathrm{n}}\right)=\text { const, } \mathrm{y}_{2}\left(\Theta_{\mathrm{n}}\right)=\text { const }, \ldots \ldots ., \mathrm{y}_{\mathrm{n}}\left(\Theta_{\mathrm{n}}\right)=\text { const }
$$

for subsequent diagnostic measurements $\Theta_{\mathrm{n}} ; \mathrm{n}=1,2, \ldots ., \mathrm{j}$, the set $\mathrm{Y}(\Theta)$ is a set of constant input parameters independent from $\Theta_{n}$, which can be written as:

$$
\mathrm{Y}\left(\Theta_{\mathrm{n}}\right)=\text { const }
$$




\section{Set of environmental parameters $\mathrm{Z}(\Theta)$}

Set of environmental parameters (interferences) $Z(\Theta)$ that can affect the working conditions of the object is a collection of elements:

$$
\mathrm{Z}(\Theta)=\left\{\mathrm{z}_{1}(\Theta), \mathrm{z}_{2}(\Theta), \ldots \ldots, \mathrm{z}_{\mathrm{n}}(\Theta)\right\}
$$

where: $z_{i}(\Theta), i=1,2, . ., n-$ parameters influencing the object's functions and recorded output parameters (diagnostic signals) generated during the operation of the object. These parameters are related to the conditions of how the object is mounted, conditions of surroundings, instability of the test conditions, interferences in the measuring equipment, influence of other cooperating objects, etc.

The adopted criterion regarding the environmental parameters (interferences) is to minimise the influence of interferences on the measured parameters of diagnostic signals, i.e.:

$$
\mathrm{Z}(\Theta)=\min
$$

or providing a comparable level of interference for subsequent diagnostic measurements (realisations) $\Theta_{\mathrm{n}}, \mathrm{n}=1,2$, ...., j, i.e.:

$$
\mathrm{Z}(\Theta)=\text { const }
$$

\section{Set of technical condition parameters - features of the object $\mathbf{X}(\Theta)$}

The set of technical condition parameters (features) of object assemblies $\mathrm{X}(\Theta)$ contains the following features:

$$
\mathrm{X}(\Theta)=\left\{\mathrm{x}_{1}(\Theta), \mathrm{x}_{2}(\Theta), \ldots ., \mathrm{x}_{\mathrm{k}}(\Theta)\right\}
$$

where: $x_{i}(\Theta), i=1,2, . ., k$ - features describing the reliability status of the k of object's assemblies. For the constructed diagnostic and reliability model, in which the binary reliability model was assumed, each $\mathrm{x}_{\mathrm{i}}$ can take values of 0 or 1 (functional, failed).

\section{Set of output (diagnostic) parameters $S(\Theta)$}

The set of output parameters $S(\Theta)$ is a set of measured diagnostic parameters containing the following elements:

$$
\mathrm{S}(\Theta)=\left\{\mathrm{s}_{1}(\Theta), \mathrm{s}_{2}(\Theta), \ldots ., \mathrm{s}_{\mathrm{n}}(\Theta)\right\}
$$

where: $s_{\mathrm{ij}}(\Theta)$-the value of the $\mathrm{i}$-th measured diagnostic parameter for the $j$-th measurement (time $\Theta_{\mathrm{n}}$ ).

The output parameters are obtained as a result of measurements of the diagnostic signal parameters made in the time interval $\Theta_{\mathrm{n}}$. These measurements can be made, for example, from the beginning of the service life $\Theta_{1}$ to $\Theta_{\mathrm{k}}$, which is the end of operating time, in $\mathrm{n}$ moments in time. We assume that the $i$-th output parameter $(i=1,2, \ldots, n)$ contains the values from the linearly ordered set of $U_{i}$ called the range of variability of the $i$-th output parameter.

If in the process of perceiving the value of the object's features (indirectly by means of diagnosing) the following were assumed:

$$
\mathrm{Y}\left(\Theta_{\mathrm{n}}\right)=\text { const }
$$

and

$$
\mathrm{Z}\left(\Theta_{\mathrm{n}}\right)=\text { const }
$$

than general diagnostic model has the form:

$$
\mathrm{S}(\Theta)=\mathrm{f}[\mathrm{X}(\Theta)],
$$

which means that if we assume constant conditions of the object's operation and constant values of the environmental parameters (interferences), then the object's output parameters will only be a function of the technical condition parameters (features) of the object.

\section{Diagnostic and reliability model}

The diagnostic and reliability model is a model combining the reliability states of object systems with the values of diagnostic signal parameters, therefore for its elaboration the following were determined:

- space of reliability states of the object,

- equations of binary (reliability) states of the object,

- model equations.

\section{Construction of state space}

The state $\mathrm{X}$ of the object is described by the set of status parameters of individual object systems:

$$
\mathrm{X}=\left\{\mathrm{x}_{1}, \mathrm{x}_{2}, \mathrm{x}_{3}, \ldots \ldots, \mathrm{x}_{\mathrm{k}}\right\}
$$

During the implementation of tasks, the object changes its properties, which is manifested in the changes in the values of the features that describe it. In practice, changes in the values of features are generally perceived in discrete form (due to periodic measurements of diagnostic parameters).

\section{Construction of model equations}

Diagnostic parameters assume values in space:

$$
U=\underset{i=1}{\times} U_{i}
$$

where: $U_{i}(i=1, \ldots, n)-$ is the range of variability of the i-th diagnostic parameter.

Values of diagnostic parameters $s=\left[s_{1} s_{2} \ldots s_{n}\right] \in U$ are dependent on the physical state of the object $\mathrm{x}=\left[\mathrm{x}_{1}, \mathrm{x}_{2}, \ldots\right.$, $\left.\mathrm{x}_{\mathrm{k}}\right] \in \mathrm{W}$. The ideal situation would be if the system of recorded diagnostic parameters depended in a deterministic and unambiguous manner on the selected system of states of the object. Then this relationship can be expressed functionally in the following form:

$$
\begin{aligned}
& s_{1}=f_{1}\left(x_{1}, x_{2}, \ldots, x_{k}\right) \\
& s_{2}=f_{2}\left(x_{1}, x_{2}, \ldots, x_{k}\right) \\
& s_{n}=f_{n}\left(x_{1}, x_{2}, \ldots, x_{k}\right),
\end{aligned}
$$

or shorter with vector notation:

$$
s=f(x)
$$

In order to identify functional relationships between the signal parameter vector and the object's state vector, taking into account the specificity of the experimental issues, probabilistic and statistical methods must be used. The use of the probabilistic model is required due to the existence of interferences caused mainly by the practical limitation of both the finite number of parameters of the diagnostic signal and the finite length of the object's state vector. 


\section{Construction of binary states}

In practice, as already mentioned, the exact value of the status of individual elements of the object (e.g. the value of clearance) is not always important, as the qualitative classification of the state of the object, its systems or assemblies is sufficient. The binary classification of the states of the object, its systems or assemblies takes place by means of established permissible limit states.

Let ' 0 ' indicate the state 'functional', while ' 1 ' indicates the state 'failed'. The task is to determine the relationship between reliability states of systems or assemblies of an object $\mathrm{x}_{\mathrm{i}} \in\{0,1\}, \mathrm{i}=1,2, \ldots, \mathrm{k}$ with output parameters (signals) including a random error:

$$
\mathrm{s}=\mathrm{f}\left(\mathrm{x}_{1}, \mathrm{x}_{2}, \ldots, \mathrm{x}_{\mathrm{k}}, \varepsilon\right)
$$

As a probabilistic model, a system of qualitative regression equations with additive random errors was chosen:

$$
\begin{aligned}
& \mathrm{s}_{1}=\beta_{10}+\beta_{11} \mathrm{x}_{1}+\beta_{12} \mathrm{x}_{2}+\ldots+\beta_{1 \mathrm{k}} \mathrm{x}_{\mathrm{k}}+\varepsilon_{1} \\
& \mathrm{~s}_{2}=\beta_{20}+\beta_{21} \mathrm{x}_{1}+\beta_{22} \mathrm{x}_{2}+\ldots+\beta_{2 \mathrm{k}} \mathrm{x}_{\mathrm{k}}+\varepsilon_{2} \\
& \mathrm{~s}_{\mathrm{n}}=\beta_{\mathrm{n} 0}+\beta_{\mathrm{n} 1} \mathrm{x}_{1}+\beta_{\mathrm{n} 2} \mathrm{x}_{2}+\ldots+\beta_{\mathrm{nk}} \mathrm{x}_{\mathrm{k}}+\varepsilon_{\mathrm{n}}
\end{aligned}
$$

It should be noted that in the given system of equations the dependent variables $s_{1}, s_{2}, \ldots, s_{n}$ are of quantitative type, and the independent variables $\mathrm{x}_{1}, \mathrm{x}_{2}, \ldots, \mathrm{x}_{\mathrm{n}}$ are of qualitative type (binary).

Based on experimental data, the parameters of the probabilistic regression model can be estimated, as a result of which a system of regression equations is obtained:

$$
\begin{gathered}
\widehat{\mathrm{s}}_{1}=\hat{\beta}_{10}+\hat{\beta}_{11} \mathrm{x}_{1}+\hat{\beta}_{12} \mathrm{x}_{2}+\cdots+\hat{\beta}_{1 \mathrm{k}} \mathrm{x}_{\mathrm{k}} \\
\widehat{\mathrm{s}}_{2}=\hat{\beta}_{20}+\hat{\beta}_{21} \mathrm{x}_{1}+\hat{\beta}_{22} \mathrm{x}_{2}+\cdots+\hat{\beta}_{2 \mathrm{k}} \mathrm{x}_{\mathrm{k}} \\
\widehat{\mathrm{s}}_{\mathrm{n}}=\hat{\beta}_{\mathrm{n} 0}+\hat{\beta}_{\mathrm{n} 1} \mathrm{x}_{1}+\hat{\beta}_{\mathrm{n} 2} \mathrm{x}_{2}+\cdots+\hat{\beta}_{\mathrm{nk}} \mathrm{x}_{\mathrm{k}}
\end{gathered}
$$

The above set of equations can be written as the following matrix:

$$
\widehat{\mathrm{s}}^{\mathrm{T}}=\widehat{\beta} \mathrm{x}^{\mathrm{T}}
$$

where: $\widehat{s}^{\mathrm{T}}$ - transposed matrix of diagnostic signals, $\hat{\beta}-$ regression coefficient matrix, $\mathrm{x}^{\mathrm{T}}$ - transposed matrix of the engine states.

The system of regression equations determined on the basis of experimental data was used to determine the states of the object, its systems or assemblies coming from the population for which this system of equations was determined.

With the vector of signals s of the tested object and the matrix $\hat{\beta}$ of the estimated parameters of the model, the reliability states of individual object systems were estimated from the transformed dependence (14) in the form of:

$$
x^{T}=\hat{\beta}^{-1} x^{T}
$$

\section{Construction of the diagnostic model at the object's system level}

Assuming the decomposition of systems into assemblies, one can determine the vector of states of the assem- blies that make up individual systems. An analogous assumption was made as for systems where the states of the assemblies are binary and the system of $\mathrm{n}$ diagnostic signals remains constant. It was also assumed that the parameters of the diagnostic signals $s=\left[s_{1}, s_{2}, \ldots, s_{n}\right]$ are determined by the state of the assemblies that make up the individual ob-

\begin{tabular}{|c|c|c|c|c|c|c|c|c|c|}
\hline \multicolumn{3}{|c|}{$\mathrm{X}_{1}$} & \multicolumn{3}{|c|}{$\mathrm{X}_{2}$} & & \multicolumn{3}{|c|}{$\mathrm{X}_{\mathrm{z}}$} \\
\hline $\bar{x}$ & .. & $\bar{\Xi}$ & $\bar{x}$ & .. & $\overline{\text { ป }}$ & .. & $\bar{x}$ & .. & 首 \\
\hline
\end{tabular}
ject systems.

Let $\mathrm{x}_{\mathrm{ij}}$ denote the state of the $\mathrm{j}$-th assembly of the $\mathrm{i}$-th system $(i=1,2, \ldots, k)$, which takes the values 0 or 1 ; in this case the description of states can be summarised in the form of Table 1 .

Table 1. Description of states at the level of engine systems and assemblies states of systems states of assemblies

The approach described earlier at the systems level was used to build this model. It is assumed that the change in the state of any of the assemblies of the i-th system affects the change of at least one of the output signals. The goal is to estimate object states at the assembly level based on the diagnostic signal vector. After adopting the same assumption for assemblies, as before for systems, the task is to determine the relationship between reliability states $x_{j} \in$ $\{0,1\}\left(j=1,2, \ldots, m_{i}\right)$ of the assemblies of the $i$-th system and signals $\mathrm{s}=\left[\mathrm{s}_{1}, \mathrm{~s}_{2}, \ldots, \mathrm{s}_{\mathrm{n}}\right]$.

As a probabilistic model for the i-th system of the object, a system of regression equations with additive random errors and binary states of assemblies was adopted:

$$
\begin{aligned}
& \mathrm{s}_{1}=\beta_{\mathrm{i} 10}+\beta_{\mathrm{i} 11} \mathrm{x}_{\mathrm{i} 1}+\beta_{\mathrm{i} 12} \mathrm{x}_{\mathrm{i} 2}+\ldots .+\beta_{\mathrm{i} 1 \mathrm{~m}_{\mathrm{i}}} \mathrm{x}_{\mathrm{im}_{\mathrm{i}}}+\varepsilon_{\mathrm{i} 1} \\
& \mathrm{~s}_{2}=\beta_{\mathrm{i} 20}+\beta_{\mathrm{i} 21} \mathrm{x}_{\mathrm{i} 1}+\beta_{\mathrm{i} 22} \mathrm{x}_{\mathrm{i} 2}+\ldots .+\beta_{\mathrm{i} 2 \mathrm{~m}_{\mathrm{i}}} \mathrm{x}_{\mathrm{im} \mathrm{i}}+\varepsilon_{\mathrm{i} 2} \\
& \mathrm{~s}_{\mathrm{n}}=\beta_{\mathrm{in} 0}+\beta_{\mathrm{in} 1} \mathrm{x}_{\mathrm{i} 1}+\beta_{\mathrm{in} 2} \mathrm{x}_{\mathrm{i} 2}+\ldots+\beta_{\mathrm{inm}_{\mathrm{i}}} \mathrm{x}_{\mathrm{im}_{\mathrm{i}}}+\varepsilon_{\mathrm{in}}
\end{aligned}
$$

In the given system of equations, the diagnostic signals $\mathrm{s}_{1}, \mathrm{~s}_{2}, \ldots, \mathrm{s}_{\mathrm{n}}$ are of the quantitative type, while the states $\mathrm{x}_{\mathrm{ij}}$, $\mathrm{j}=1,2, \ldots, \mathrm{m}_{\mathrm{i}}$ take binary values.

The introduced model parameters for the i-th system:

$$
\beta_{\mathrm{i}}=\left[\begin{array}{cccc}
\beta_{\mathrm{i} 10} & \beta_{\mathrm{i} 11} & \ldots & \beta_{\mathrm{i} 1 \mathrm{~m}_{\mathrm{i}}} \\
\beta_{\mathrm{i} 20} & \beta_{\mathrm{i} 21} & \ldots & \beta_{\mathrm{i} 2 \mathrm{~m}_{\mathrm{i}}} \\
\ldots & \ldots & \ldots & \ldots \\
\beta_{\mathrm{in} 0} & \beta_{\mathrm{in} 1} & \ldots & \beta_{\mathrm{inm}_{\mathrm{i}}}
\end{array}\right]
$$

and interference of diagnostic signals that are unknown:

$$
\varepsilon_{\mathrm{i}}=\left[\varepsilon_{\mathrm{i} 1}, \varepsilon_{\mathrm{i} 2}, \ldots, \varepsilon_{\mathrm{in}}\right]
$$

It is obvious that the actual parameter values $\beta_{\mathrm{i}}$ and interference values cannot be calculated. It is assumed, however, that the interferences have a normal distribution with an expected value of 0 and unknown, but equal, variances. With this assumption it is possible to estimate the parameters of the probabilistic regression model, based on experimental data, as a result of which a system of regression equations for the i-th system of the object can be obtained 


$$
\begin{aligned}
& \widehat{\mathrm{s}}_{1}=\hat{\beta}_{\mathrm{i} 10}+\hat{\beta}_{\mathrm{i} 11} \mathrm{x}_{\mathrm{i} 1}+\hat{\beta}_{\mathrm{i} 12} \mathrm{x}_{\mathrm{i} 2}+\cdots+\hat{\beta}_{\mathrm{i} 1 \mathrm{~m}_{\mathrm{i}}} \mathrm{x}_{\mathrm{im} \mathrm{i}} \\
& \widehat{\mathrm{s}}_{2}=\hat{\beta}_{\mathrm{i} 20}+\hat{\beta}_{\mathrm{i} 21} \mathrm{x}_{\mathrm{i} 1}+\hat{\beta}_{\mathrm{i} 22} \mathrm{x}_{\mathrm{i} 2}+\cdots+\hat{\beta}_{\mathrm{i} 2 \mathrm{~m}_{\mathrm{i}}} \mathrm{x}_{\mathrm{im} \mathrm{i}} \\
& \widehat{\mathrm{s}}_{\mathrm{n}}=\hat{\beta}_{\mathrm{in} 0}+\hat{\beta}_{\mathrm{in} 1} \mathrm{x}_{\mathrm{i} 1}+\hat{\beta}_{\mathrm{in} 2} \mathrm{x}_{\mathrm{i} 2}+\cdots+\hat{\beta}_{\mathrm{inm}_{\mathrm{i}}} \mathrm{x}_{\mathrm{im} \mathrm{i}}
\end{aligned}
$$

which can be written as the following matrix:

$$
\widehat{s}^{T}=\widehat{\beta}_{i} x_{i}^{T}
$$

where: $\widehat{\mathbf{s}}^{\mathrm{T}}-$ transposed matrix of diagnostic signals, $\widehat{\beta}-$ matrix of regression coefficient for the $\mathrm{i}$-th system of the object, $\mathrm{x}^{\mathrm{T}}$ - transposed matrix of states of the assemblies of the i-th system.

Having the given signal vector s of the examined object and the matrix $\widehat{\beta}_{\mathrm{i}}$ of the estimated parameters of the model, it is possible to estimate the states of individual assemblies of the i-th system, using the formula:

$$
x_{i}^{T}=\widehat{\beta}_{i}^{-1} s^{T}
$$

Knowledge of the coefficients of the system, however, does not allow to estimate the discrepancy between the estimated and actual states of the assemblies, the more so because the estimated states do not take binary values, but are real numbers. To determine the intensity of the relationship between the actual parameters of the diagnostic signal $s$ and estimated values $\hat{s}$ the coefficient of determination $\mathrm{R}^{2}=\mathrm{R}^{2}(\mathrm{~s}, \hat{\mathrm{s}})$ was used.

The determination coefficient, as a normalised measure of linear relationship between the diagnostic signal and the states of the assemblies that make up the subsequent systems of the object, is the basis for the selection of equations. Equations with determination coefficients that are as close as possible to 1 should be chosen. The low value of the determination coefficient indicates a weak relation between the actual parameters of the diagnostic signal $s$ and the estimated values $\hat{\mathrm{s}}[1]$.

The diagnostic states of the object $\mathrm{s}$ are a vector of random variables with the expected value:

$$
E\left(s^{T}\right)=\beta_{i} x_{i}^{T}
$$

Coefficients $\hat{\beta}$ of the model:

$$
\widehat{\mathrm{s}}^{\mathrm{T}}=\widehat{\beta}_{\mathrm{i}} \mathrm{x}_{\mathrm{i}}^{\mathrm{T}},
$$

that estimates the states of the assemblies of the i-th object's system as functions of a random sample, are random variables - estimators of the actual values of the object's parameters. These estimators, obtained on the basis of the minimum of the sum of squares, are unbiased.

\section{Model identification}

The identification of the diagnostic and reliability model at the object assembly level was based on the results of the diagnostic observation of an internal combustion engine of a rail vehicle under operating conditions. The scope of the research was carried out according to the principles of the passive-reliability experiment [7].

The columns of the matrix of observation results contain observed diagnostic parameters; the rows contain the realisations of parameters, which were normalised to the first meas- urement (the first realisation of a given parameter) separately for each signal parameter, according to the following formula:

$$
s_{i, j}^{n}=\frac{s_{i, j}}{s_{i, 1}}
$$

where: $s_{i, j}^{n}$ - normalised value of the i-th signal parameter for the $j$-th measurement (realisation), $s_{i, j}$ - actual value of the $\mathrm{i}$-th parameter for the $\mathrm{j}$-th measurement (realisation), $\mathrm{s}_{\mathrm{i}, 1}$ - actual value of the $\mathrm{i}$-th parameter for the first measurement (realisation).

As a result of normalisation, dimensionless parameter values are obtained, thus it is not necessary to consider various ranges of their values and various units. The normalised parameter values are an indicator of the parameter's changes for subsequent realisations and a measure of the sensitivity of the individual parameters to changes in the state of the engine.

On the basis of reliability data (acquired during the experiment), a binary matrix of reliability (qualitative) states of individual engine systems was created, assuming ' 0 ' as the 'functional' state and ' 1 ' as the 'failed' state of the engine, for the same values of locomotive mileage as in case of the measurement of the signal vector.

For such prepared data, calculations were made based on a developed digital simulator. Linear regression calculations were performed separately for each parameter of the vibration signal treated as a (dependent) variable. The reliability states ( 0 or 1$)$ of individual engine systems were used as independent variables. As a result of the calculations, values of regression coefficients were obtained, and then according to the relationship (12), systems of regression equations.

An example of the equation with a constant value for Ask (effective value of vibration acceleration) is the equation (27) and without this constant - the equation (28).

$$
\begin{gathered}
\text { Ask }=1.175-0.19 \cdot \mathrm{KOR}-0.38 \cdot \mathrm{PAL} \\
+1.1435 \cdot \mathrm{SMA}-0.505 \cdot \mathrm{WYM}-0.248 \cdot \mathrm{GLO} \\
+0.4037 \cdot \mathrm{ROZ}-0.027 \mathrm{CHL}+0.4656 \cdot \mathrm{POZ} \\
\quad \mathrm{Ask}=-0.134 \cdot \mathrm{KOR}-0.338 \cdot \mathrm{PAL} \\
+2.1531 \cdot \mathrm{SMA}-0.409 \cdot \mathrm{WYM}-0.145 \cdot \mathrm{GLO} \\
+0.9606 \cdot \mathrm{ROZ}-0.639 \cdot \mathrm{CHL}+0.2518 \cdot \mathrm{POZ}
\end{gathered}
$$

where: KOR - crank system, PAL - fuel system, SMA lubrication system, WYM - scavenging system, GLO engine heads, ROZ - timing system, CHL - cooling system, POZ - other engine systems.

The presented equations (25) and (26) allow, based on the measured effective value of vibration accelerations, to determine the reliability status of the internal combustion engine systems.

\section{Model verification}

Regression coefficients $\beta$, calculated on the basis of experimental data, created a matrix of regression coefficients, from which a square matrix was selected, for which the signal parameters obtained the highest values of the determination coefficient $\mathrm{R}^{2}$ [9].

For the example shown, these were the following parameters of the vibration signal:

Aav - average value of vibration acceleration,

Ask - effective value of vibration acceleration, 
Xav - average value of vibration displacement,

Xsk - effective value of vibration displacement,

Xsz - peak value of vibration displacement,

$\mathrm{Kx}$ - shape coefficient of vibration displacement,

fx - rice frequency of vibration displacement,

$\mathrm{Hv}$ - harmonic factor of vibration velocity.

The matrix obtained from the regression coefficients with the biggest $\mathrm{R}^{2}$ is a square matrix with 8 columns and rows. In the presented example, the assessment of the engine's condition at the level of its main systems was adopted.

A system of non-constant regression equations was adopted for further analysis. Such a set of equations, assuming that all the engine systems are functional, does not contain any terms and the equation equals zero, which means that the whole engine is in functional state. However, when an engine system or systems fail, then the equation has terms corresponding to these failed systems.

Matrix $\beta$ of regression coefficients with the largest $R^{2}$ was inverted and multiplied by columns corresponding to subsequent measurements (realisations) of the transposed matrix of standardised signal symptoms. After multiplying the inverted matrix of the regression coefficients by normalised values of the signal parameters, the theoretical states of individual engine systems were obtained. These were then normalised to the maximum obtained value.

Figure 2 presents exemplary results of calculated theoretical states and actual states of engine systems observed in operation.

The actual statuses observed in operation are shown in the figures in the form of bars taking the value ' 0 ' ('functional' state) and the value ' 1 ' ('failed' state). The calculated states of the engine systems are shown in the form of points connected by a line. If the calculated value of the system state equals to $x_{i}>0$, then the system is in the 'failed' state; if, however, the calculated value of the system state equals to $x_{i} \leq 0$, the system is in the 'functional' state. The presented results of calculations were satisfactory while assessed with values of diagnostic signal parameters known from operation.

Based on the results of the calculations of the state of the engine systems obtained in the presented example, the probability of correctness of the diagnosis was calculated according to the formula (27). It can be considered as an indicator of the model's compliance with the real object.

$$
\mathrm{P}_{\mathrm{d}}=\frac{\mathrm{n}_{\mathrm{e}}}{\mathrm{n}_{\mathrm{s}}}
$$

where: $P_{d}-$ probability of correctness of the diagnosis, $n_{e}-$ number of engine system states for which the state determined from the calculation is consistent with the state registered in operation, $\mathrm{n}_{\mathrm{s}}-$ total number of engine system states.

For the presented example, the probability of a correctness of the diagnosis amounts to $\mathrm{P}_{\mathrm{d}}=0.75$.

\section{Conclusions}

The article presents a developed diagnostic and reliability model of a complex mechanical object, for which validation of results and verifications was carried out on the example of the internal combustion engine systems of a rail vehicle. This model has been developed assuming that on the basis of the vector of the vibration signal parameters it is possible to assess the technical condition of a complex object by adopting a two-state model of operation and maintenance.
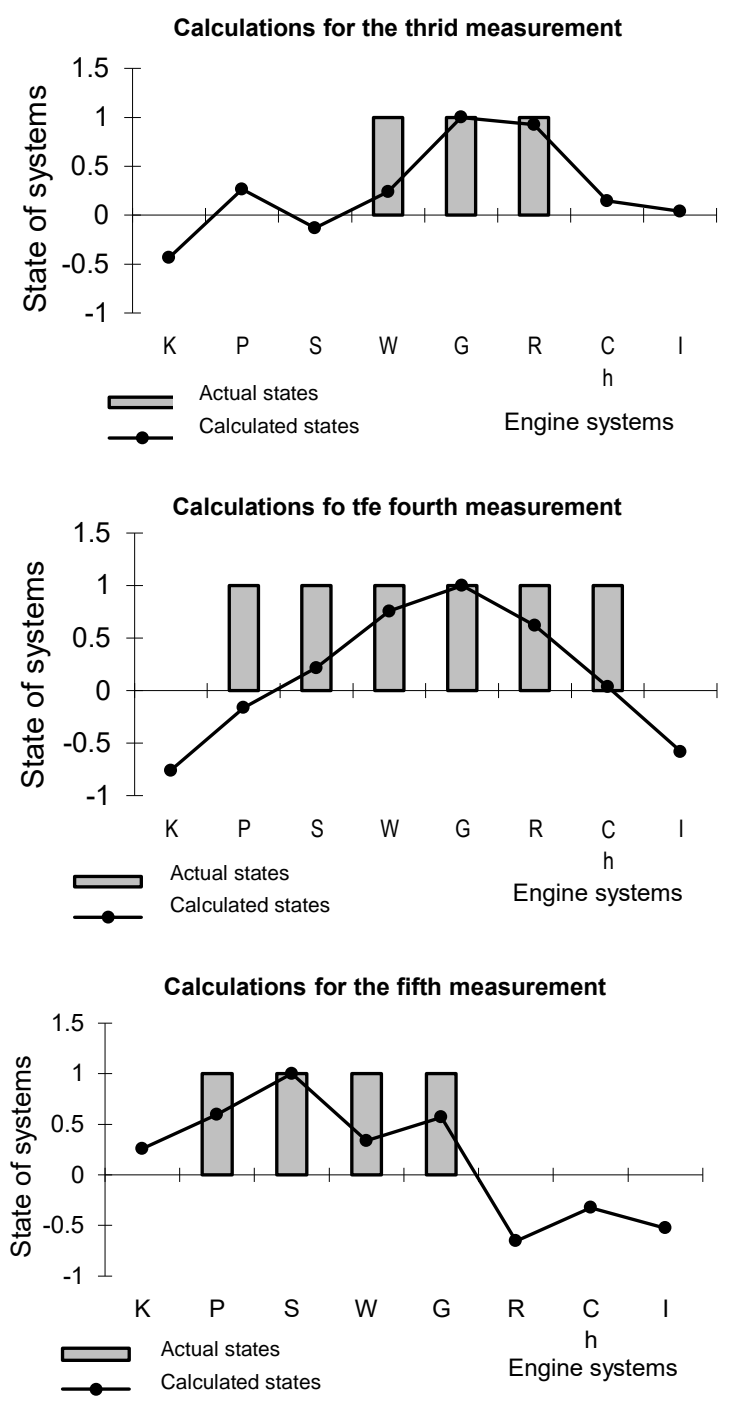

Fig. 2. The results of calculations of the engine systems states for the third measurement in operation of engine

The verification of the developed diagnostic and reliability model of a complex mechanical object allows to specify the following conclusions:

- for a complex mechanical object, it is possible to determine a diagnostic model binding the parameters of the vibration signal - quantitative assessment - with the parameters of the state of its systems - quality assessment, - on the basis of the presented and verified diagnostic and reliability model, with knowledge of the signal parameters, it is possible to determine the (binary) reliability states of the internal combustion engine and its systems, it is possible to use the developed diagnostic and reliability model for other complex mechanical objects.

\section{Acknowledgements}

Presented research and the paper are partly funded by Statutory Activities fund of the Institute of Combustion Engines and Transport, PUT (PL) 5/52/DSPB/1277. 


\section{Bibliography}

[1] AMPUŁA, D. Regresja jako metoda procesu predykcji. Problemy Techniki Uzbrojenia. 2014, 130, 67-78.

[2] BOBROWSKI, D. Probabilistyka w zastosowaniach technicznych. WNT. Warszawa 1980.

[3] CEMPEL, C. Podstawy wibroakustycznej diagnostyki maszyn. WNT. Warszawa 1982.

[4] GAVRILIUK, E.A., MANTSEROV, S.A. Fuzzy reliability model of systems for decision support in technical diagnostics. Proceedings of the II International Scientific and Practical Conference "Fuzzy Technologies in the Industry" (FTI 2018), Ulyanovsk, 2018.

[5] MURPHY, M.D., PAASCH, R. Reliability centered prediction technique for diagnostic modeling and improvement. Research in Engineering Design. 1997, 9(1), 3545.

[6] NIZIŃSKI, S., RYCHLIK, A. Model diagnostyczny złożonego obiektu technicznego. Biuletyn WAT. 2011, LX, 1, 195-209.

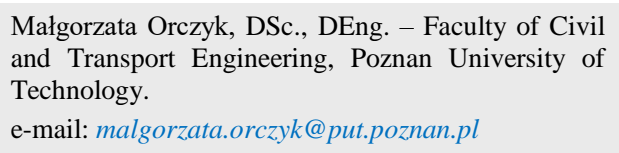

[7] ORCZYK, M., TOMASZEWSKI, F. Method of reduction of diagnostic parameters during observation on the example of a combustion engine. MATEC Web of Conferences. 2017, 118, 00034.

https://doi.org/10.1051/matecconf/201711800034

[8] PIELECHA, I., SKOWRON, M., WISŁOCKI, K. Mathematical models formulation for the delay of SIDI injectors opening based on optical tests. Combustion Engines. 2016, 167(4), 8-21. https://doi.org/10.19206/CE-2016-402

[9] RABIEJ, M. Statystyka z programem Statistica. Wydawnictwo Helion. Gliwice 2012.

[10] SZYMAŃSKI, G.M., MISZTAL, W. Analysis of measurement points sensitivity of vibration signals on the stand of jet engine. Combustion Engines. 2017, 171(4), 279-282. https://doi.org/10.19206/CE-2017-448

[11] TOMASZEWSKI, F. Diagnostyczno-niezawodnościowe modele regresyjne silnika spalinowego lokomotywy. DIAGNOSTYKA 2000, II Międzynarodowy Kongres Diagnostyki Technicznej. 239-240, Warszawa, 2000.

Prof. Franciszek Tomaszewski, DSc., DEng.

Faculty of Civil and Transport Engineering, Poznan University of Technology.

e-mail: franciszek.tomaszewski@put.poznan.pl 